\title{
HISTORIAS DE LA CONQUISTA
}

\author{
ASPECTOS DE LA HISTORIOGRAFÍA \\ DE TRADICIÓN INDÍGENA
}

\author{
STORIES OF THE CONQUEST \\ ASPECTS OF THE INDIGENOUS TRADITION \\ HISTORIOGRAPHY
}

\begin{abstract}
Pastrana Flores, Miguel (2004), Historias de la Conquista. Aspectos de la historiografía de tradición indígena, México, UNAM-Instituto de Investigaciones Históricas, 298 pp., cuadros, ilus. (Serie: Teoría e Historia de la Historiografía, 2), ISBN: 970-32-1449-5
\end{abstract}

Este 2021 se cumplen cinco siglos de la conquista de México. A lo largo del año se desarrollarán múltiples proyectos conmemorativos que redundarán en la presentación de coloquios, encuentros y jornadas para discutir críticamente el proceso histórico; en la publicación de estudios que penetren con novedosos enfoques teórico-metodológicos en temas hasta ahora ignorados, y en la edición de nuevas fuentes que enriquezcan el corpus documental disponible para el estudio del tema.

La conmemoración de la Conquista también es un buen momento para retomar los trabajos que por su calidad se han convertido en lecturas obligadas para aquellos interesados tanto en el conocimiento del complejo proceso histórico, como en las múltiples lecturas que la conciencia histórica de diversos tiempos y espacios le han dado. Ese es el caso de la obra que a continuación reseño. Me refiero a Historias de la conquista. Aspectos de la historiografía de tradición indígena, de Miguel Pastrana Flores, publicado en 2004 por el Instituto de Investigaciones Históricas de la UNAM $(\mathrm{IIH}-$ UNAM). El libro, que es la versión revisada y mejorada del trabajo que seis años antes
Pastrana Flores presentó como tesis doctoral, ha tenido una buena recepción entre los especialistas, por lo que en 2009 tuvo su primera reimpresión y en 2017 el IIH lo incluyó en su catálogo de publicaciones digitales de acceso libre.

Según Pastrana, su trabajo "sólo es uno más en la larguísima serie de estudios" ( $p$. 8) que han abordado la Conquista. No obstante, la obra ofrece relevantes aportes. Según explica el propio autor, él no "pretende estudiar el proceso mismo de la Conquista, sino analizar y explicar cómo se le presenta en la historiografía de tradición indígena" ( $p$. 8). Así pues, la originalidad de su libro radica en dos aspectos. En primer lugar, en que, a diferencia de los múltiples trabajos enfocados en la perspectiva española, Pastrana ofrece un estudio centrado en la mirada de los nahuas. $Y$ en segundo, en que su análisis es de corte historiográfico, es decir que desmenuza los discursos de un conjunto de obras de tradición indígena para discernir cuál fue la conciencia histórica que los nahuas del siglo XVI y XVII tuvieron acerca del sometimiento armado.

Desde luego, la propuesta de Pastrana Flores tiene una sólida vena historicista que 
se refleja en la influencia de autores como Edmundo O'Gorman y Ramón Iglesia, quienes desde la cuarta década del siglo XX insistieron en que las obras de historia no eran "minas de donde extraer ciertos datos" para conocer el pasado (O'Gorman), sino que en ellas está presente "el historiador con sus ideas, con sus pasiones, con sus 'parcialidades', dadas por el lugar y la época en que la escribió" (Iglesia), y esto permite estudiar la conciencia que los grupos humanos han forjado sobre su pasado. A pie de página, el propio Pastrana reconoce el adeudo que su estudio tiene "con la perspectiva de análisis asumida por Ramón Iglesia con respecto a las crónicas de tradición española” (p. 7) en su libro Cronistas e historiadores de la conquista de México (1942).

Para realizar el análisis de la conciencia histórica náhuatl sobre la Conquista, Pastrana elige cuatro temas fundamentales, que a su vez le permiten estructurar su libro, pues a cada uno de ellos le dedica un apartado. Los temas son: 1. Los presagios, 2. La naturaleza de los españoles, 3. Motecuhzoma ante la Conquista y 4 . El sentido de la Conquista. El último apartado lo podríamos considerar como una especie de conclusión, pues en él hilvana las observaciones vertidas en los tres primeros.

Pastrana Flores es consciente de que las obras historiográficas de tradición náhuatl "son resultado de un largo proceso de conciencia histórica" (p. 9) y que, en ese sentido, no componen un bloque homogéneo, sino que se diversificaron en múltiples tradiciones. Para su estudio sobre la Conquista, él eligió obras pertenecientes a cinco de esas tradiciones: 1. La tlatelolca, en la que incluye a los Anales de Tlatelo/co, la columna en náhuatl del Libro Doce del Códice florentino, la versión en español de fray Bernardino de Sahagún en el mismo códice y otra versión de la Conquista, también en español, que fue enmendada por el propio franciscano; 2. La tenochca, compuesta por los documentos relacionados con lo que Robert Barlow Ilamó "la Crónica X", es decir, la Historia de las Indias de Nueva España e islas de Tierra Firme de fray Diego Durán, la
Crónica mexicana de Hernando de Alvarado Tezozómoc, el Manuscrito Tovar de fray Juan de Tovar y su copia con variantes conocida como Códice Ramírez, además del Códice Aubin; 3. La tlaxcalteca, de la que retomó el Lienzo de Tlaxcala, las Pinturas tlaxcaltecas de la Conquista, la Descripción de la ciudad y provincia de Tlaxcala y la Historia de Tlaxcala, estas dos últimas de la autoría de Diego Muñoz Camargo; 4. La acolhua, en la que incluyó las obras de Fernando de Alva Ixtlilxóchitl, principalmente el Compendio histórico del reino de Tetzcoco y la Historia de la nación chichimeca; y 5. La chalca, compuesta por la Primera, Tercera, Cuarta, Séptima y Octava relación de Chimalpahin Cuauhtlehuanitzin, así como el Memorial breve acerca de la fundación de la ciudad de Culhuacan. Ocasionalmente, el autor agrega al análisis obras cuya tradición no es claramente identificable, pero que son fundamentales para el tema, como los escritos de Cristóbal del Castillo y la Historia de los mexicanos por sus pinturas (pp. 9-13).

Como podrá notarse, en el corpus documental fijado por Pastrana se incluyen autores de raigambre indígena, pero también cronistas españoles (Sahagún, Durán, etcétera), no obstante, el conjunto está bien pensado, pues el estudioso aclara que en la categoría de historiografía de tradición náhuatl están contenidas

todas aquellas obras históricas que recogen la información, los conceptos, el punto de vista y, sobre todo, los relatos estructurados de los grupos indígenas de habla náhuatl, aunque los autores inmediatos sean españoles o mestizos, religiosos, civiles o funcionarios. Lo importante es que manifiesten, en algún grado y medida, conciencia histórica indígena [...] (p. 9).

Cada apartado del libro Historias de la conquista presenta la misma estructura y está acompañado de cuadros informativos que abonan a la claridad de la exposición. El autor comienza con un recorrido historiográfico en el que explica cuáles han sido las principales formas en que el tema aborda- 
do ha sido interpretado por la historiografía del siglo XVI al XX. Posteriormente indica el problema historiográfico al que intentará dar respuesta. Luego expone la forma en que los nahuas prehispánicos concebían el tema. Y finalmente analiza su corpus historiográfico para explicar cómo las ideas de tradición indígena están presentes en la interpretación que los nahuas del siglo XVI y XVII le dieron a cada tema abordado.

En el primer apartado, "Los presagios", Pastrana señala que la historiografía de los siglos XVI al XX no han logrado dar respuesta a preguntas como: ¿cuál es el lugar que ocupan los presagios en la historiografía de tradición náhuatl? y ¿qué función cumplen en la explicación de la Conquista? (p. 21). Con estas interrogantes abre un interesante subapartado, en el que aclara cuáles eran las características que los nahuas le atribuían a los tetzahuitl, vocablo que en el contexto colonial fue traducido como "presagio" y que hacía referencia a portentos espantosos y oscuras señales de los dioses que anunciaban el futuro, pero cuyo sentido era asignado a posteriori ( $p$. 24). Asimismo, profundiza en la relevancia de los tetzahuitl en la concepción indígena de la historia, para luego analizar el sentido de los múltiples presagios de la Conquista dentro del pensamiento náhuatl. Una de las conclusiones del estudioso es que para "los nahuas novohispanos los presagios fueron un recurso ideológico tradicional que les permitió explicarse la Conquista española en los términos de su propia cultura" ( $p$. 30). Este enfoque desde la tradición indígena permite a Pastrana refutar con sólidos argumentos las ideas de estudiosos como Guy Rozat que han explicado el sentido de los presagios desde la matriz cultural europea, negando toda presencia de tradición indígena en ellos. Para Pastrana "no se trata de presagios copiados del cristianismo o de la antigüedad clásica. Su tratamiento ciertamente puede revelar toques cristianos, pero el núcleo del significado está en la tradición religiosa náhuatl” (p. 53).

Respecto al segundo apartado, dedicado a "La naturaleza de los españoles", después de hacer su revisión crítica por la historiografía de los siglos XVI al XX, Pastrana Flores destaca que, salvo Eulalia Guzmán, la mayoría de los autores siguieron una postura tradicional que consistió en señalar que los indígenas, y en particular los mexicas, identificaron a los españoles como dioses debido a que en buena parte de las crónicas de tradición indígena se les llamó teteo o teteu, que es el plural de teotl o teutl, "dios" (pp. 65-70). El estudioso considera que esta identificación no resuelve problema alguno, pues deja abiertas preguntas como: “¿Si eran dioses, por qué se relacionaban con ellos como humanos?, ¿por qué los Ilamaban así?, ¿si después fue evidente que eran hombres, por qué los siguieron llamando dioses?" (p. 71).

A partir de estas preguntas Pastrana señala los diversos significados que los nahuas le dieron a la palabra teotl (pp. 7174) y, con base en la propuesta de Alfredo López Austin, explica cuáles eran las características del hombre-dios en Mesoamérica, e identifica, a partir de las figuras de Martín Océlotl y Andrés Mixcóatl, cuáles pudieron ser las del hombre-dios para los nahuas de la primera mitad del siglo XVI (p. 74). Finalmente, el autor analiza su corpus de obras de tradición indígena para esclarecer si, en efecto, los nahuas identificaron a los españoles como dioses. Curiosamente, lo que pudo observar es que en realidad en la historiografía náhuatl "los castellanos son presentados tanto con características sobrehumanas como plenamente humanas" (p. 114), que sus atributos no coinciden con los de Martín Océlot y Andrés Mixcóatl, y que la relación que entablaron con los conquistadores fue la que se establecía con grupos humanos, es decir, de carácter político y militar, y no ritual y religioso. Con estas conclusiones preliminares Pastrana plantea un segundo problema: ¿por qué en las crónicas se les siguió llamando dioses? Para el autor, puede haber dos posibles respuestas: una, que tiene que ver con que el concepto teot/ no siempre significa "dios"; y la otra -que propone a partir de una idea inicial de Eulalia Guzmán- es que su designación 
como teules en realidad deriva del vocablo teuhtli, "señor" (pp. 115 y 116). En este caso debemos destacar que el conocimiento de la lengua náhuatl fue fundamental para que Pastrana pudiera argumentar con firmeza sus propuestas.

Por otra parte, Pastrana Flores explica que la personalidad del tlahtoani Motecuhzoma Xocoyotzin ha sido "motivo de diversas opiniones a lo largo de casi quinientos años de esfuerzo historiográfico" (p. 120). Por tal motivo, el tercer apartado, "Motecuhzoma ante la conquista", es particularmente extenso. A pesar de que en el siglo XVI la historiografía española, ligada a los conquistadores, caracterizó al gobernante mexica con una excelsitud "proporcional a la grandeza de la empresa de Conquista” (p. 121), el estudioso explica cómo entre los siglos XVII al XIX se construyó una representación negativa del gobernante tenochca, primero como un hombre soberbio y atemorizado por sus creencias, y luego como un "inepto [...] fanático, cobarde y afeminado" (p. 123). En esta revisión hay que destacar la aguda crítica de Pastrana a la historiografía del siglo XX, sobre todo a la interpretación hispanista de Carlos Pereyra, al indigenismo de Eulalia Guzmán y a las interpretaciones míticas de Michel Graulich y Susana Gillespie, pues aunque los juicios hacia Motecuhzoma fueron "más serenos y moderados", no por ello fueron "más comprensivos" (p. 125). Para Pastrana Flores, el principal impedimento para comprender el comportamiento de Motecuhzoma ante la Conquista es que la mayoría de autores han ubicado el análisis "desde la perspectiva occidental del buen y el mal gobierno, sin tratar de penetrar en la idea misma que los nahuas tenían del cargo del tlatoani y del ejercicio del poder" (p. 128).

Eso es lo que él hace.Con base en el análisis de los huehuetlahtolli del Libro Sexto del Códice florentino y de la Historia general de Sahagún, el autor destaca la relación entre el poder y las deidades, así como las normas que el mandatario debía respetar y el autocontrol de las emociones que debía poseer para evitar caer en la peor de las fal- tas: la soberbia (p. 208). Con base en esta información de tradición indígena, Pastrana analiza la forma en que su corpus documental representó el gobierno de Motecuhzoma (pp. 135-208) y observa que todas "tienden a señalar graves transgresiones a las normas del buen gobierno: se le acusa de ser soberbio, de ser cruel con los ancianos y los sacerdotes, de cometer injusticias sobre los macehuales, de mostrar cobardía e incapacidad de mando, faltas todas que lo alejan del buen gobierno y de la divinidad" (p. 209).

Por último, en el cuarto apartado del libro, Pastrana Flores pasa revista por los múltiples sentidos que la historiografía ha dado a la Conquista. En esta parte es interesante su apunte respecto a que las obras desde el siglo XVI hasta el XX -a excepción de Salvador Toscano y Eulalia Guzmán ( $p$. 220) - , han coincidido en ponderar los beneficios culturales que la Conquista aportó al Ilamado Nuevo Mundo. También merece especial atención la ubicación que el estudioso le da a la Visión de los vencidos (1959) de Miguel León-Portilla en este proceso historiográfico. Con agudeza crítica, Pastrana destaca su condición de antología de textos nahuas traducidos por Ángel María Garibay, su carácter divulgativo y la carencia de un análisis crítico. Según el autor, León-Portilla sólo "pretendía llamar la atención sobre la posibilidad de realizar estudios sobre la interpretación náhuatl de la Conquista" ( $p$. 220), pero no los desarrolló.

Podemos decir que Pastrana atendió el reto planteado por León-Portilla buscando el sentido que los nahuas le atribuyeron a la Conquista; sin embargo, sobre sus conclusiones no anticiparemos mucho. Sólo diremos que con sus observaciones finales el autor cierra de forma redonda su libro, lo cual se puede observar si tomamos en cuenta la idea de Ramón Iglesia planteada en el epígrafe inicial (p. 5), según la cual la percepción de la conquista de México se puede refractar en diversas direcciones dependiendo de la perspectiva desde la que se observe. De la misma forma, Pastrana señala que el corpus de obras que analizó no da 
cuenta de un solo sentido de la Conquista, sino de múltiples (p. 267), los cuales esperamos que nuestro lector descubra a través de la consulta directa de este relevante estudio sobre los discursos que los nahuas de los siglos XVI y XVII forjaron para intentar comprender su presente novohispano.

Sergio Ángel Vásquez Galicia

UNAM sergiovasquez@filos.unam.mx

\section{Sergio Ángel Vásquez Galicia}

Es licenciado, maestro y doctor en Historia por la Universidad Nacional Autónoma de México (UNAM). Medalla "Alfonso Caso" en 2008. Realizó su Estancia Posdoctoral en el Posgrado en Historiografía de la Universidad Autónoma Metropolitana, unidad Azcapotzalco (2015-2016). Es especialista en historiografía de tradición indígena y cultura náhuatl. Desde 2014 es profesor de asignatura del Colegio de Historia de la Facultad de Filosofía y Letras de la UNAM, en donde imparte la materia "Introducción a la cultura náhuatl" y el seminario "Fuentes y temas de cultura náhuatl". Su publicación más reciente es: "Los indios del Nuevo Mundo en el esquema cristiano de la historia universal según fray Diego Durán", Revista de Historia de América, núm. 158, México, enero-junio de 2020, pp. 13-40. https://doi. org/10.35424/rha.158.2020.475 